\title{
Analiza zmian patologicznych w badaniu endoskopowym górnego odcinka przewodu pokarmowego u pacjentów przygotowywanych do planowej operacji kardiochirurgicznej
}

\section{Analysis of pathological changes in gastroscopy of upper gastrointestinal tract in a group of cardiosurgery patients}

\author{
Paweł Walerowicz ${ }^{1 凶}$, Andrzej Biskupski ${ }^{1}$, Lidia Kędzierska ${ }^{2}$, Mirosław Brykczyński ${ }^{1}$ \\ 1 Pomorski Uniwersytet Medyczny w Szczecinie, Klinika Kardiochirurgii, al. Powstańców Wlkp. 72, 70-111 Szczecin \\ ${ }^{2}$ Samodzielny Publiczny Szpital Kliniczny nr 2 Pomorskiego Uniwersytetu Medycznego w Szczecinie, Centralna Pracownia Endoskopowa, \\ al. Powstańców Wlkp. 72, 70-111 Szczecin \\ $\triangle$ pawel.walerowicz@gmail.com
}

\begin{abstract}
Introduction: Nowadays, treatment of cardiovascular system diseases relies on the suppression of activity of the coagulation system, which can decrease the risk of thrombus incidents. Ambulatory treatment relies on drugs which inhibit platelet activity, or the use of oral anticoagulants. Currently, new oral anticoagulants are gaining increasing popularity. Micromolecular heparin is used preoperatively and perioperatively, while heparin is almost always used during cardiac surgery. Erosion or ulcer in the upper gastrointestinal tract (UGIT) may increase the risk of bleeding from UGIT.
\end{abstract}

The aim of the study was to analyse the prevalence of inflammatory changes in gastroscopy performed before elective cardiac surgery.

Conclusions: Inflammatory findings of the upper gastrointestinal tract were observed in more that $50 \%$ of patients before cardiac surgery. Preoperative diagnosis and pharmacological preventive protocol reduce the risk of bleeding from the upper gastrointestinal tract.

Keywords: cardiosurgery; gastroscopy; acetylic acid.

\begin{abstract}
ABSTRAKT
Wstęp: Współczesne leczenie chorób sercowo-naczyniowych w znacznym stopniu opiera się na hamowaniu czynności układu krzepnięcia krwi mającego na celu zmniejszenie ryzyka wystąpienia incydentów zatorowo-zakrzepowych. Leczenie to w warunkach ambulatoryjnych opiera się na podawaniu leków hamujących czynność płytek krwi lub stosowaniu antykoagulantów doustnych. Obecnie coraz większą popularnością cieszą się leki z grupy nowoczesnych antykoagulantów doustnych. W okresie przed-i okołooperacyjnym używane są heparyny drobnocząsteczkowe, a w czasie samej operacji kardiochirurgicznej praktycznie zawsze stosowana jest heparyna. Obecność nadżerek lub wrzodów w górnym odcinku przewodu pokarmowego
\end{abstract}

(GOPP) u operowanych pacjentów może zwiększać ryzyko okołooperacyjnego krwawienia z GOPP.

Celem pracy była analiza częstości występowania zmian patologicznych w GOPP u chorych przygotowywanych do planowych operacji kardiochirurgicznych.

Wnioski: W badaniu endoskopowym zmiany patologiczne w GOPP stwierdzono u ponad 50\% chorych przygotowywanych do planowych operacji kardiochirurgicznych. Przedoperacyjna diagnostyka i protokół ochrony farmakologicznej redukują ryzyko krwawienia z GOPP.

Słowa kluczowe: kardiochirurgia; gastroskopia; kwas acetylosalicylowy.

\section{WSTĘP}

W monografii dotyczącej roli kwasu acetylosalicylowego (ASA) w prewencji chorób naczyniowo-sercowych Milner i Hoffhines przypominają rzadko dziś cytowane prace, które opublikował Lawrence L. Craven [1]. W latach 50. XX w. autor ten po raz pierwszy opisał zastosowanie ASA w prewencji chorób serca $[2,3]$. Prace randomizowane, podkreślające rolę ASA w prewencji chorób serca, oparte na dużych populacjach pacjentów, pojawiły się pod koniec lat 80. XX w. [4, 5].
Bardzo duże dawki (500-1000 mg) ASA znacząco wydłużały czas protrombinowy i były odpowiedzialne za częste krwawienia [1]. Dokładne poznanie mechanizmu działania ASA w hamowaniu agregacji płytek pozwoliło na zmniejszenie dużych dawek leku (300-500 mg). Obecnie w prewencji chorób sercowo-naczyniowych najczęściej stosuje się małe dawki ASA (75-150 mg/dobę) $[6,7,8]$. Aktualne wytyczne towarzystw naukowych oparte na rekomendacjach ekspertów nakazują stosowanie ASA w prewencji wtórnej u wszystkich chorych z rozpoznaną chorobą układu sercowo-naczyniowego. U chorych 
po ostrych zespołach wieńcowych i u pacjentów po implantacji stentów dodatkowo wdrażane są leki z grupy nowoczesnych antykoagulantów doustnych (NOAC). Migotanie przedsionków wiąże się z wdrożeniem terapii przeciwkrzepliwej lekami z grupy antykoagulantów doustnych (OAC) lub NOAC. Zalecenia sprawiają, że praktycznie każdy pacjent kwalifikowany do leczenia kardiochirurgicznego jest w trakcie przewlekłej terapii mającej na celu obniżenie krzepliwości krwi z jednego, a często nawet z dwóch lub trzech wskazań. Ryzyko krwawienia wzrasta znacząco u osób stosujących leki z tych grup. Wyniki badań McCarthy'ego wskazują na występowanie owrzodzeń i nadżerek błony śluzowej w górnym odcinku przewodu pokarmowego (GOPP) u 20\% pacjentów zażywających długotrwale ASA [9]. Krwawienie z przewodu pokarmowego związane z operacjami kardiochirurgicznymi nie jest powikłaniem często spotykanym, gdyż dotyczy ok. 1,5\% pacjentów [9]. Wiąże się jednak z dużą śmiertelnością, która sięga blisko 40\% [10, 11]. Powikłanie to, wymagające transfuzji krwi, postępowania endoskopowego lub chirurgicznego, istotnie zwiększa ryzyko zgonu, a także podnosi znacząco koszty hospitalizacji [12]. Dlatego niezwykle ważnym problemem jest podjęcie decyzji o zakończeniu lub podtrzymaniu terapii lekami obniżającymi krzepnięcie przed rozpoczęciem planowej operacji.

Podsumowując, należy podkreślić, że pierwsze opisy dotyczące krwawień z GOPP po ASA ukazały się wcześniej, niż wykonano pierwsze operacje serca w krążeniu pozaustrojowym oraz opublikowano pierwsze prace o roli ASA w prewencji wtórnej i pierwotnej [1].

Celem pracy była ocena częstości występowania i rodzaju zmian chorobowych w GOPP u pacjentów przygotowywanych do planowej operacji kardiochirurgicznej. Dodatkowo analizowano, czy zastosowany w ośrodku autorów schemat postępowania mający zabezpieczyć pacjentów przed krwawieniem z GOPP jest skuteczny.

\section{MATERIAtY I METODY}

Badanie oparto na analizie retrospektywnej dokumentacji 1144 pacjentów operowanych z powodu chorób serca i aorty w 2015 r. Do grupy badanej wstępnie zakwalifikowano 833 pacjentów przygotowywanych do operacji w trybie planowym. Ostateczną analizę oparto na wynikach badań endoskopowych i danych klinicznych 602 osób, u których badanie endoskopowe GOPP wykonano w pracowni endoskopii Samodzielnego Publicznego Szpitala Klinicznego nr 2 (SPSK-2). Odstąpiono od analizy wyników badań endoskopowych wykonanych w innych pracowniach i oddziałach z powodu trudności w interpretacji oraz porównaniu niektórych wyników opisowych.

Od wielu lat endoskopia wchodzi w skład panelu badań przedoperacyjnych przygotowujących pacjentów do planowej operacji w SPSK-2. Na badanie te kierowano pacjentów w czasie wizyty kwalifikacyjnej przed operacją serca. W przypadku wykrycia zmian patologicznych takich jak zapalenie błony śluzowej GOPP wdrażano leczenie inhibitorami pompy protonowej (IPP). Termin planowanej operacji pozostawiano bez zmian. W przypadku rozpoznania nadżerek i wrzodów wdrażano leczenie IPP oraz rozszerzano diagnostykę o badanie w kierunku infekcji Helicobacter pylori. Jeśli w badaniu potwierdzono infekcję, wówczas choremu zalecana była eradykacja. Taka sytuacja najczęściej wiązała się z koniecznością czasowego odroczenia planowanej operacji serca. Decyzję o badaniu kontrolnym GOPP po eradykacji i leczeniu IPP podejmował gastrolog, zazwyczaj tylko u chorych z czynną chorobą wrzodową lub licznymi nadżerkami.

Wszystkie dane kliniczne i informacje o zmianach patologicznych w badaniu endoskopowym GOPP gromadzono od chwili przyjęcia pacjenta w przychodni przyklinicznej do chwili wypisu po operacji serca.

Grupa badana obejmowała 602 pacjentów w średnim wieku $63,3 \pm 9,6$ lat. W grupie tej było $454(75,42 \%)$ mężczyzn oraz 148 (24,58\%) kobiet (tab. 1). Choroba wieńcowa była izolowanym wskazaniem do leczenia operacyjnego za pomocą pomostowania aortalno-wieńcowego u 404 (67,1\%) pacjentów. Wada serca lub choroba aorty ze współistniejącą chorobą wieńcową była wskazaniem do operacji u 72 (11,2\%) osób. Izolowane wady zastawkowe lub choroby aorty były powodem 119 (19,8\%) operacji. Z innych powodów zoperowano 7 (1,2\%) pacjentów z grupy badanej.

TABELA 1. Grupa badana

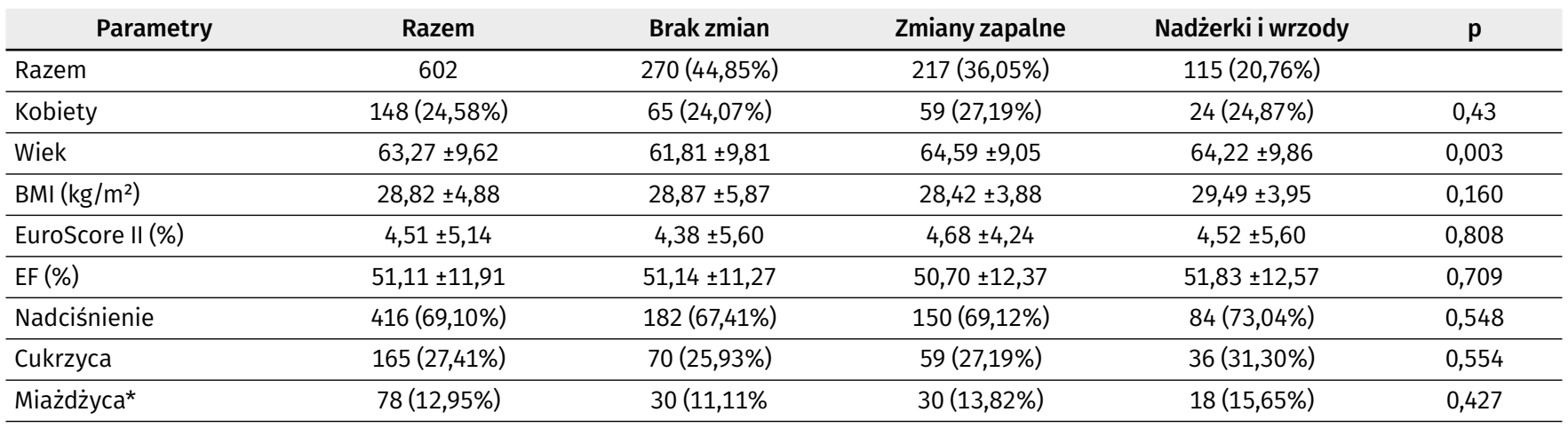

* Pacjenci z odnotowanym w historii choroby istotnym dystansem chromania z powodu miażdżycy kończyn dolnych lub potwierdzonym badaniem USG zwężeniem tętnic szyjnych. 
TABELA 2. Zmiany patologiczne w górnym odcinku przewodu pokarmowego w zależności od rodzaju wykonanej operacji

\begin{tabular}{|c|c|c|c|c|c|}
\hline Parametry & Razem & Brak zmian & Zmiany zapalne & Nadżerki i wrzody & p \\
\hline Razem & 602 & 270 & 217 & 115 & \\
\hline CABG & 404 & $173(42,8 \%)$ & $147(36,4 \%)$ & $84(20,79 \%)$ & 0,223 \\
\hline CABG i zastawki & 72 & $29(40,27 \%)$ & $32(44,44 \%)$ & $11(15,28 \%)$ & 0,271 \\
\hline Zastawki i tętniaki & 119 & $64(53,78 \%)$ & $37(31,09 \%)$ & $18(15,13 \%)$ & 0,087 \\
\hline Inne & 7 & $4(57,1 \%)$ & $1(14,3 \%)$ & $2(28,6 \%)$ & \\
\hline $\begin{array}{l}\mathrm{p} \\
\mathrm{CABG} / \text { nie } \mathrm{CABG}\end{array}$ & & 0,006 & 0,121 & 0,299 & \\
\hline
\end{tabular}

CABG - pomostowanie aortalno-wieńcowe

\section{WYNIKI}

Zmiany patologiczne w czasie endoskopii GOPP stwierdzono u 332 (55,15\%) pacjentów. Nie stwierdzono żadnych zmian chorobowych w GOPP u $270(44,85 \%)$ badanych. Zmiany o charakterze zapalenia błony śluzowej stwierdzono u 217 (36,05\%) osób. Nadżerki wykryto u 103 (17,11\%), a wrzody u 22 (3,65\%) badanych. Z uwagi na podobną etiologię, leczenie i ryzyko krwawienia do dalszych analiz połączono grupy pacjentów z nadżerkami i z wrzodami (tab. 2).

W trakcie kontrolnych gastroskopii wykryto także nowotwór żołądka u 71-letniego mężczyzny i bezoar u 57-letniego mężczyzny.

Za pomocą analizy statystycznej zgromadzonego materiału wykazano dodatnią korelację występowania zmian w obrazie endoskopowym wraz z wiekiem pacjentów $(p=0,003)$. Potwierdzono też częstsze występowanie zmian patologicznych w endoskopii GOPP u pacjentów operowanych z powodu choroby wieńcowej w stosunku do izolowanych wad zastawkowych lub tętniaków $(\mathrm{p}=0,006)$. Wśród powikłań pooperacyjnych obserwowanych w tej grupie nie zanotowano żadnego przypadku krwawienia z GOPP.

\section{DYSKUSJA}

Badanie endoskopowe GOPP wchodzi w skład panelu badań u pacjentów przygotowywanych do planowej operacji. Badania te obejmują także sanację jamy ustnej, ocenę nosicielstwa Staphylococcus aureus opornego lub wrażliwego na metycylinę, wyrównanie u chorych na cukrzycę poziomu hemoglobiny glikowanej HbA1c do wartości niższych od 6,5\%. Zlecano też kontrolę ginekologiczną u kobiet. Przeprowadzenie wymienionych działań ma na celu zminimalizowanie ryzyka związanego z powikłaniami okołooperacyjnymi.

Zmiany patologiczne w endoskopii obserwowano u 55,15\% pacjentów. Potencjalnie najbardziej niebezpiecznymi zmianami pod względem krwawienia śródoperacyjnego są wrzody. W związku z ich obecnością odroczono planową operację u 3,71\% mężczyzn i 4,6\% kobiet. Długotrwały stan zapalny błony śluzowej żołądka, a zwłaszcza postać zanikowa, prowadzi do rozwoju raka $[13,14]$. Analizie nie poddano czynników predysponujących do powstania zmian zapalnych w GOPP, takich jak nikotynizm, stres, alkohol czy niski status socjoekonomiczny. Pomimo wielu prób walidacji wywiadu nie zdołano uzyskać wiarygodnych wyników do analizy powyższych zmiennych.

Operacje przeprowadzono u 602 z przebadanych pacjentów. Po operacji 476 (79\%) osób, u których jedynym lub współistniejącym powodem operacji była choroba wieńcowa, powinno otrzymywać ASA do końca życia. Cukrzyca była wskazaniem do terapii ASA u 165 (27,4\%) chorych z badanej grupy. Leki z grupy OAC będzie przyjmować przewlekle 77 (12,8\%) osób, którym wszczepiono zastawki mechaniczne, oraz 6 (1\%), którym wszczepiono protezę biologiczną w pozycję mitralną. Leki z grupy OAC lub NOAC będzie przyjmować 12 (2\%) pacjentów z utrwalonym migotaniem przedsionków. U części chorych rodzaj terapii obniżającej krzepliwość krwi zostanie ustalony w okresie 3 miesięcy po operacji. Grupa 30 (5\%) osób po plastyce zastawki mitralnej będzie mogła pozostać na terapii ASA, o ile zachowają rytm miarowy. Podobnie 29 (4,9\%) pacjentów po wszczepieniu zastawki biologicznej w pozycję aortalną będzie mogło pozostać na terapii ASA, jeśli nie będzie miało zaburzeń rytmu serca. U 108 (17,9\%) osób, u których odnotowano napady migotania przedsionków jedynie w okresie pooperacyjnym, będzie można rozważyć zakończenie terapii OAC lub NOAC.

Zastosowany schemat postępowania pozwolił na uniknięcie epizodów krwawienia z GOPP w okresie pooperacyjnym. Wdrożenie IPP u chorych przewlekle przyjmujących antykoagulanty lub leki przeciwpłytkowe jest stosowane przez wielu autorów i pozwala istotnie zmniejszyć krwawienia z GOPP [15]. Niestety szerokie wprowadzenie IPP sprzyja częstszemu występowaniu infekcji Clostridium difficile.

Wielu autorów podkreśla, że samodzielnym czynnikiem krwawienia z GOPP jest wiek $[16,17,18,19]$. W analizie własnej wiek był również istotny statystycznie na poziomie 0,003. Innym stwierdzonym czynnikiem było współistnienie choroby wieńcowej ze zmianami w GOPP. Najprawdopodobniej miało to związek z częstszym przyjmowaniu leków z grupy ASA i NOAC przez tych pacjentów.

\section{WNIOSKI}

Zmiany zapalne GOPP dotyczą większej części pacjentów przygotowywanych do planowej operacji kardiochirurgicznej. Istotnie częściej odnotowuje się je u osób ze współistniejącą chorobą wieńcową przewlekle przyjmujących preparaty ASA i u tych, które ukończyły 64. r.ż. 


\section{PIŚMIENNICTWO}

1. Milner J, Hoffhines A. The discovery of aspirin's antithrombotic effects. Tex Heart Inst J 2007;34(2):179-86.

2. Craven LL. Coronary thrombosis can be prevented. J Insur Med 1950;5(4):47-8

3. Craven LL. Experiences with aspirin (Acetylsalicylic acid) in the nonspecific prophylaxis of coronary thrombosis. Miss Valley Med J 1953;75(1):38-44.

4. Randomised trial of intravenous streptokinase, oral aspirin, both, or either among 17,187 cases of suspected acute myocardial infarction: ISIS-2. Lancet 1988;2:349-60.

5. Peto R, Gray R, Collins R, Wheatley K, Hennekens C, Jamrozik K, et al. Randomised trial of prophylactic daily aspirin in British male doctors. Br Med J (Clin Res Ed) 1988;296:313-6.

6. Antithrombotic Trialists' Collaboration. Collaborative meta-analysis of randomized trials of antiplatelet therapy for prevention of death, myocardial infarction, and stroke in high risk patients. BMJ 2002;324:71-86.

7. Hansson L, Zanchetti A, Carruthers SG, Dahlöf B, Elmfeldt D, Julius S, et al. Effects of intensive blood-pressure lowering and low-dose aspirin in patients with hypertension: principal results of the Hypertension Optimal Treatment (HOT) randomized trial. HOT Study Group. Lancet 1998;351:1755-62.

8. Dunning I, Versteegh M, Fabbri A, Pavie A, Kolh P, Lockowandt U, et al. Guideline on antiplatelet and anticoagulation management in cardiac surgery. Eur J Cardiothorac Surg 2008;34(1):73-92. doi: 10.1016/j. ejcts.2008.02.024.

9. McCarthy DM. Nonsteroidal antiinflammatory drug-induced ulcers: management by traditional therapies. Gastroenterology 1989;96:662-74

10. D'Ancona G, Baillot R, Poirier B, Dagenais F, de Ibarra JI, Bauset R, et al. Determinants of gastrointestinal complications in cardiac surgery. Tex Heart Inst J 2003;30(4):280-5.
11. Suleiman MS, Zacharowski K, Angelini GD. Inflammatory response and cardioprotection during open-heart surgery: The importance of anaesthetics. Br J Pharmacol 2008;153(1):21-33. doi: 10.1038/sj.bjp. 0707526.

12. Brykczyński M, Listewnik MJ, Kowalik B, Butkiewicz J, Żyluk A, Prowans P. Krwawienie z górnego odcinka przewodu pokarmowego u chorych po operacjach serca w krążeniu pozaustrojowym. Pol Przegl Chir 1996;68:335-6.

13. Andersson B, Nilsson J, Brandt J, Höglund P, Andersson R. Gastrointestinal complications after cardiac surgery. Br J Surg 2005;92(3):326-33. doi: $10.1002 /$ bjs. 4823 .

14. Correa P. Human gastric carcinogenesis: a multistep and multifactorial process. First American Cancer Society Award Lecture on Cancer Epidemiology and Prevention. Cancer Res 1992;52(24):6735-40.

15. Biskupski A, Korzonek M, Brykczyński, Kowalik B, Wiechowski S. Prewencja krwawień z górnego odcinka przewodu pokarmowego u chorych operowanych z powodu chorób serca w Klinice Kardiochirurgii Pomorskiej Akademii Medycznej w Szczecinie. Ann UMCS Sect D 2005; 60: 145-9.

16. Ramakrishnan K, Salinas R. Peptic ulcer disease. Am Fam Physician 2007;76(7):1005-12.

17. Feinstein LB, Holman RC, Christensen KL, Steiner CA, Swerdlow DL. Trends in hospitalizations for peptic ulcer disease, United States, 1998-2005. Emerg Infect Dis 2010;16(9):1410-8. doi: 10.3201/eid1609.091126.

18. Campbell NR, Hull RD, Brant R, Hogan DB, Pineo GF, Raskob GE. Aging and heparin-related bleeding. Arch Intern Med 1996;156(8):857-60.

19. Pilotto A, Franceschi M, Leandro G, Paris F, Niro V, Longo MG, et al. The risk of upper gastrointestinal bleeding in elderly users of aspirin and other non-steroidal anti-inflammatory drugs: the role of gastroprotective drugs. Aging Clin Exp Res 2003;15(6):494-9. 